\title{
Stuchtey, Benedikt, Die europäische Expansion und ihre Feinde. Kolonialismuskritik vom 18. bis in das 20. Jahrhundert
}

Fanny Dufétel-Viste

\section{OpenEdition}

Journals

Édition électronique

URL : http://journals.openedition.org/ifha/6579

DOI : $10.4000 /$ ifha. 6579

ISSN : 2198-8943

Éditeur

IFRA - Institut franco-allemand (sciences historiques et sociales)

Référence électronique

Fanny Dufétel-Viste, "Stuchtey, Benedikt, Die europäische Expansion und ihre Feinde. Kolonialismuskritik vom 18. bis in das 20. Jahrhundert », Revue de l'IFHA [En ligne], Date de recension, mis en ligne le 01 janvier 2011, consulté le 22 septembre 2020. URL : http://journals.openedition.org/ifha/6579 ; DOI https://doi.org/10.4000/ifha.6579

Ce document a été généré automatiquement le 22 septembre 2020.

(C)IFHA 


\title{
Stuchtey, Benedikt, Die europäische Expansion und ihre Feinde. Kolonialismuskritik vom 18. bis in das 20. Jahrhundert
}

\author{
Fanny Dufétel-Viste
}

1 Dans cet ouvrage l'auteur se place dans la perspective de l'histoire des idées : il s'est inspiré d'approches anglo-saxonnes, comme l'intellectual history de Stefan Collini, ou des méthodes de la Cambridge School de Quentin Skinner. Il tend à démontrer qu'il est impossible de réduire les critiques du colonialisme à un schéma unique, même s'il perçoit chez les intellectuels qui se sont opposés aux impérialismes une commune insatisfaction face à l'état du monde, un pessimisme certain par opposition à l'optimisme et à la confiance inébranlable des impérialistes. Des thèmes se font de même certes écho, mais il ne s'agit pas d'une histoire cohérente avec une logique linéaire stricte : chaque pays, chaque période a ses spécificités liées au contexte national.

2 Trois grandes parties structurent sa réflexion. Dans la première partie, après être remonté à l'épisode colonial espagnol en Amérique du Sud et à la controverse de Valladolid en 1550, il se penche sur la période des Lumières. La critique morale s'y double alors d'une critique économique. Le système colonial avec son protectionnisme et ses grandes sociétés détenant des monopoles est perçu par des économistes tel Adam Smith comme une configuration inefficace. Les écrits de cette période esquissent un monde meilleur, libéré du colonialisme. Aucune échéance n'est cependant fixée: il s'agit plutôt d'un horizon d'attente indéfini et lointain.

3 La deuxième partie s'intéresse plus spécifiquement au cas de l'Angleterre entre 1815 et 1882. Pour l'auteur un thème central de la critique du colonialisme est alors la notion de grandeur et décadence. Les parallèles entre l'empire britannique et l'empire romain sont alors nombreux. L'appétit de conquêtes et de richesses ne connaissant plus de limites va entraîner une dégradation des mœurs et la chute, inévitable, d'un monde 
devenu trop arrogant. L'auteur s'oppose d'ailleurs fermement dans cette deuxième partie à la thèse selon laquelle la pensée anti-impérialiste aurait été marginale, voire absente des débats politiques dans l'Angleterre victorienne. Les scandales coloniaux en sont un parfait exemple, qu'il s'agisse du soulèvement indien de 1857 ou du scandale autour de l'affaire Eyre, du nom d'un gouverneur anglais en Jamaïque. L'impact immédiat dans les médias est alors révélateur de l'importance de l'affaire.

Dans la troisième partie il étudie aussi le cas de l'Allemagne, de la France ou des ÉtatsUnis. Pour l'auteur on ne saurait parler d'une voie américaine spécifique par rapport à l'impérialisme européen. Le fait colonial est un enjeu de pouvoir et d'opposition entre blocs politiques et au sein des parlements. Les ambivalences sont multiples : certains groupes, tel le parti socialiste allemand, vont longtemps voir dans le fait colonial la mission civilisatrice. Il suffirait selon eux de corriger les excès pour arriver à une version acceptable.

Le bilan établi par l'auteur de l'anti-colonialisme est en demi-teinte. La majorité de la population est restée indifférente ou a gardé une vision positive du colonialisme. Selon B.S., de nombreux critiques ont de plus sous-estimé l'importance du fait colonial dans la construction d'une identité nationale. Ils ont souvent été perçus comme à rebours de la modernité, ou du moins de ce qui était perçu alors comme la modernité. Mais ils ont su justement pointer les limites intrinsèques à l'expansion européenne.

6 Fanny Dufétel-Viste (université Rennes II) 